\title{
Public Space Demand and Adaptive Behavior of Residents in Old Residential Area of Ancient City: Based on Qingyi Garden of Beirenyi Hutong in Kaifeng
}

\author{
Shu Zhao*, Zhe Wang \\ Henan University, China \\ *Corresponding author: Shu Zhao, 785539380@qq.com
}

\begin{abstract}
The majority of the literature on the transformation of cultural promotion space in old residential areas in the United States and abroad is written from the top-down perspective of God, such as architects, planners, developers, and even government officials, and only a few of them examine the designer's work from the perspective of aborigines. To sample life and gain insight into human nature, find another means to be as near to the public as possible, listen to the voice of users, and conduct an in-depth examination of the freestyle works altered by the old residential districts through the "people's architectural planner."
\end{abstract}

Keywords: Old residential areas; Public space; People's building planner; Freestyle works; Micro update; Empirical data

Publication date: November 2021; Online publication: November 30, 2021

\section{Introduction}

Ministry of Housing and Urban-Rural Development: during the "14th Five Year Plan period," China will complete the transformation of 219,000 old residential area in cities and towns.

When the social function of the old residential area cannot meet the needs of users, and this situation cannot be fundamentally changed in the short term, how do residents accommodate on the existing hardware conditions of the residential area. They can often make full use of the corners of sporadic space and upgrade it to become a public space carrying market culture. Through the in-depth analysis of the Freestyle works of people's architectural planners, we may be able to re-understand architecture, residential area and even life from a new perspective ${ }^{[1]}$.

\section{Empirical analysis}

\subsection{Basic information}

Qingyi Garden is located in the north section of Renyi Hutong, north of Longting District. It is a government led affordable housing project with limited price. It was completed in 2002 . The building area is 36,000 square meters, the total investment is 23.8 million yuan, the plot ratio is 2.75 , the greening rate is $25 \%$, the total number of buildings is 6 , and the total number of houses is 222 . The base is square, with three rows of buildings side by side, without central centralized green space, supporting leisure facilities and property management houses. The only public facilities are the entrance guard and gate access control system. The residential area was built at the beginning of this century and its basic positioning is not high. It belongs to affordable housing in the traditional sense. When the residents' living hardware conditions cannot meet the normal social needs, how to use the leftover space to "micro update" the environment according to local 
conditions. In this paper, various types of public space levels are sorted out in order to build a space system and achieve the purpose of reconstruction.

\section{Environmental observation and analysis}

The observation method is used to classify the public space in the original design environment of the residential area according to its physical location, which is as follows: intersection, front and rear buildings, side-by-side buildings, residential area boundary and square boundary. On this basis, the representative secondary public space is further divided. (Figure 1) ${ }^{[2]}$.

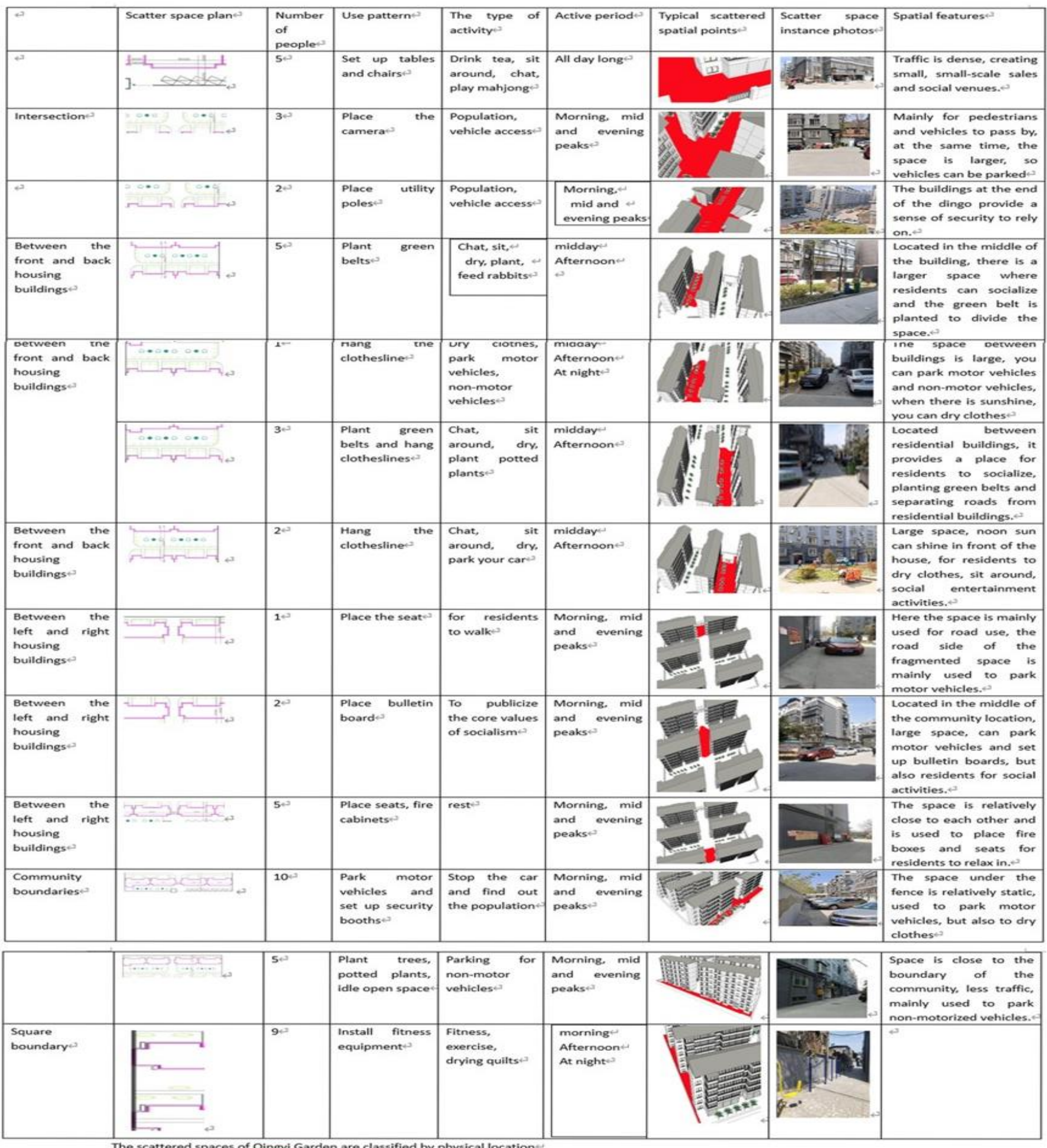

Figure 1. The Scattered Spaces of Qingyi Garden are classified by physical location. 
Classify the spontaneous transformation projects of the residential area environment in order to find the essence behind this phenomenon, such as residents' behavior, living habits, ideology and other deepseated reasons. (Figure 2, Figure 3).

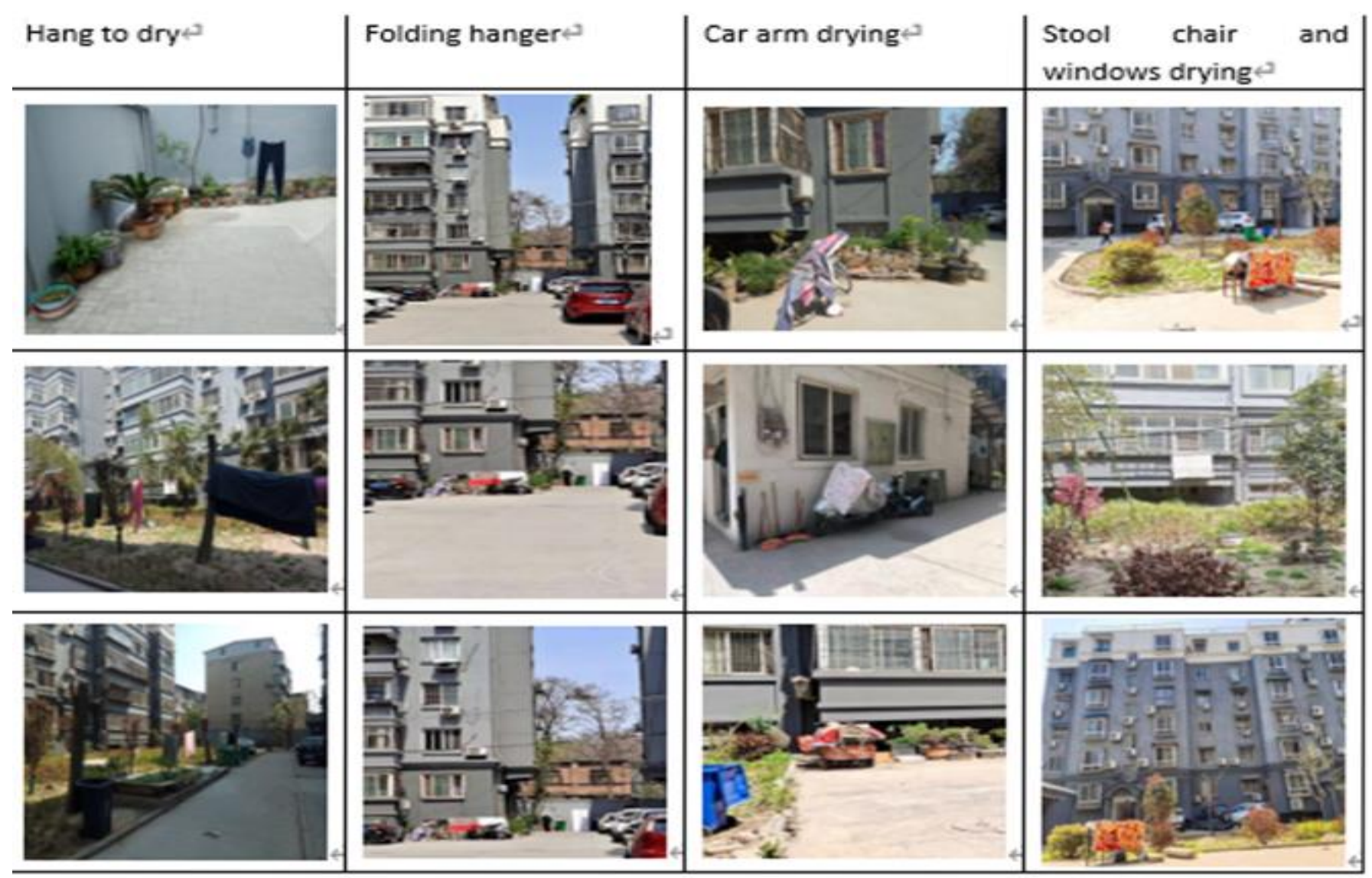

Figure 2. Drying method statistics

Summarize the main material elements in public space: street lamps, trees, seats, motor vehicles, nonmotor vehicles, clothes hangers and potted plants. (Figure 4, Figure 5, Table 1)
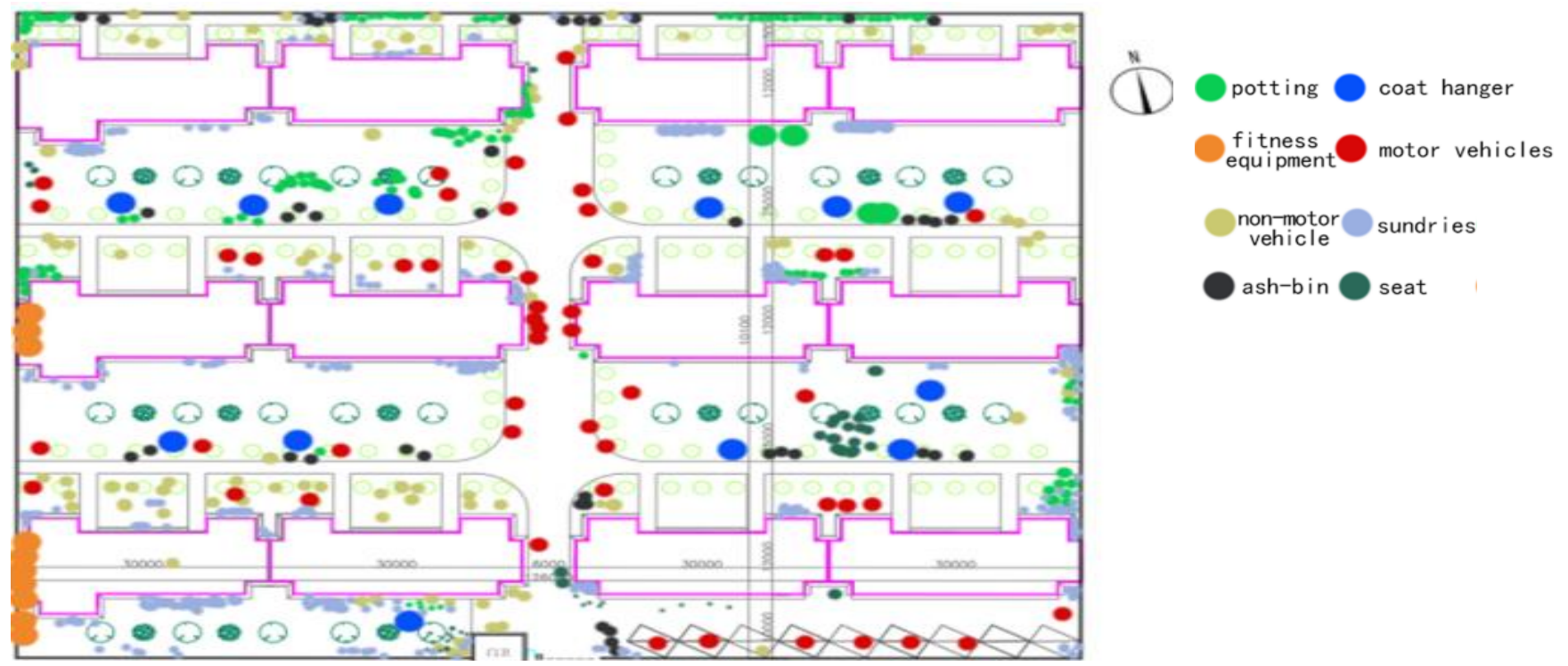

Figure 3. General layout ${ }^{[3]}$ 
Statistics of the number of material elements in each physical location space

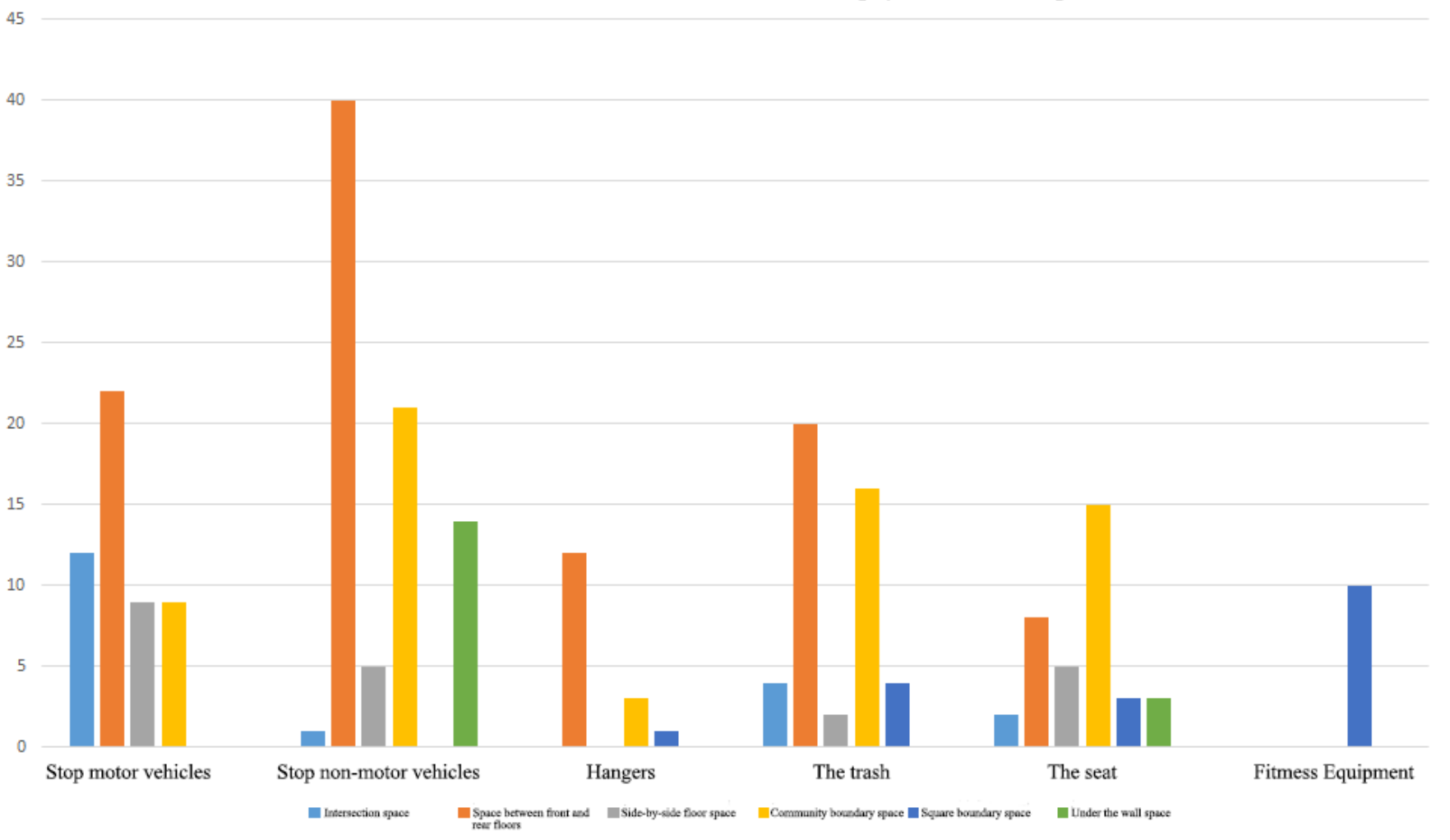

Figure 4. Statistics of the number of material elements in each physical location space

The quantity statistics of material elements in the entrance space of the community

16

12

10


Benches Non-motor vehicle Motor vehicle

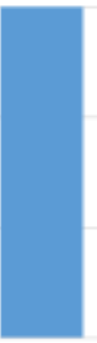

Potting
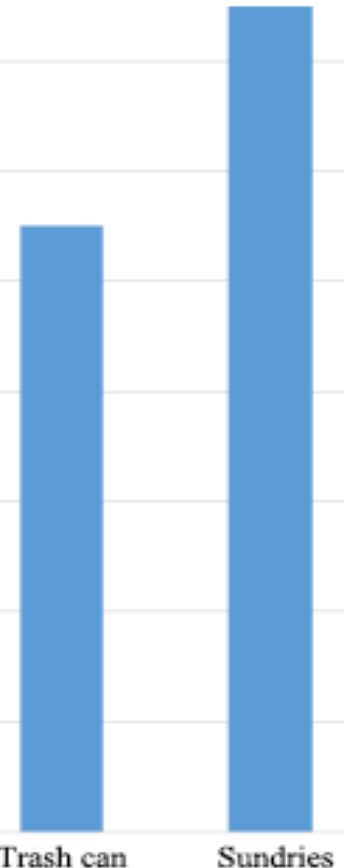

Figure 5. The quantity statistics of material elements in the entrance space of the community 
Table 1. Statistical table of space material elements in front and back of residential buildings

\begin{tabular}{|c|c|c|c|c|c|c|c|}
\hline \multicolumn{8}{|c|}{ The quantify statistics of material elements in each physical imitation space } \\
\hline & $\begin{array}{l}\text { Stop } \\
\text { motor } \\
\text { vehicles }\end{array}$ & \multicolumn{2}{|c|}{$\begin{array}{l}\text { Stop non- } \\
\text { motor } \\
\text { vehicles }\end{array}$} & Hangers & $\begin{array}{l}\text { Trash } \\
\text { can }\end{array}$ & Seat & $\begin{array}{l}\text { Fitting } \\
\text { equipment }\end{array}$ \\
\hline Intersection space & 12 & \multicolumn{2}{|l|}{1} & $\mathbf{0}$ & 4 & 2 & $\mathbf{0}$ \\
\hline $\begin{array}{l}\text { Space between front and rear } \\
\text { floors }\end{array}$ & 22 & \multicolumn{2}{|l|}{40} & 12 & 20 & 8 & $\mathbf{0}$ \\
\hline Side-by-side floor space & 9 & \multicolumn{2}{|l|}{5} & $\mathbf{0}$ & 2 & 5 & $\mathbf{0}$ \\
\hline Community boundary space & 9 & \multicolumn{2}{|l|}{21} & 3 & 16 & 15 & $\mathbf{0}$ \\
\hline Square boundary space & $\mathbf{0}$ & \multicolumn{2}{|l|}{$\mathbf{0}$} & 1 & 4 & 3 & 10 \\
\hline Under the wall space & $\mathbf{0}$ & \multicolumn{2}{|l|}{14} & $\mathbf{0}$ & $\mathbf{0}$ & 3 & $\mathbf{0}$ \\
\hline \multicolumn{8}{|c|}{ The quantity statistics of material elements in the entrance space of the community } \\
\hline \multicolumn{3}{|c|}{ Ladders } & \multicolumn{5}{|l|}{1} \\
\hline \multicolumn{3}{|l|}{ Pools } & \multicolumn{5}{|l|}{1} \\
\hline \multicolumn{3}{|l|}{ Benches } & \multicolumn{5}{|l|}{10} \\
\hline \multicolumn{3}{|l|}{ Non-motor vehicle } & \multicolumn{5}{|l|}{6} \\
\hline \multicolumn{3}{|l|}{ Motor vehicle } & \multicolumn{5}{|l|}{7} \\
\hline \multicolumn{3}{|l|}{ Potting } & \multicolumn{5}{|l|}{6} \\
\hline \multicolumn{3}{|l|}{ Trash can } & \multicolumn{5}{|l|}{11} \\
\hline \multicolumn{3}{|l|}{ Sundries } & \multicolumn{5}{|l|}{15} \\
\hline
\end{tabular}

\section{Results and discussion}

In the final analysis, the above various "upgrading" is ultimately a manifestation of the lack of life function, and the essence of any social phenomenon is still human after all. Only by thoroughly analyzing the users of these long-term relatively stable material elements can we really grasp their distribution rules and constituent factors. By analyzing and summarizing the active place, active time and activity content of residential area residents in a day, we can get the coupling law between various material factors. Through the figure below, we can get the daily adaptive activities of residents and the areas where the design needs to be improved. (Figure 6)



Figure 6. The works of people's architecture ${ }^{[3,4]}$ 
Finally, it is worth mentioning that the space originally designed to be used as a garage has been creatively transformed into a canteen by residents. It can be said that although the sparrow is small, it' may have all its internal organs, which basic cover every aspect of life (It have a business license to work with). Less than ten square meters of "cultural spots" serve as part of the functions of non-motor vehicle garages, shopping centers, community centers and even administrative centers (parliaments) to a considerable extent. Many "major events" related to each residential area resident take place here (Table 2) ${ }^{[5]}$.

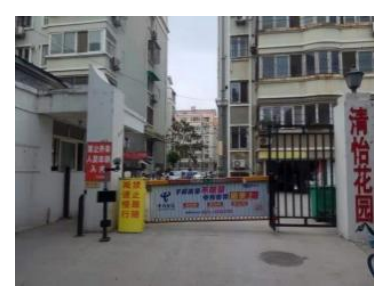

(Figure 7)

Cape of good hope

"cultural point" 1



(Figure 11)

Cape of good hope

"cultural point" 5

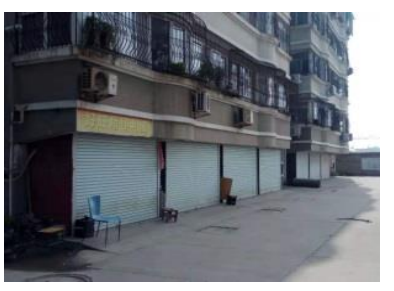

(Figure 8)

Cape of good hope "cultural point" 2

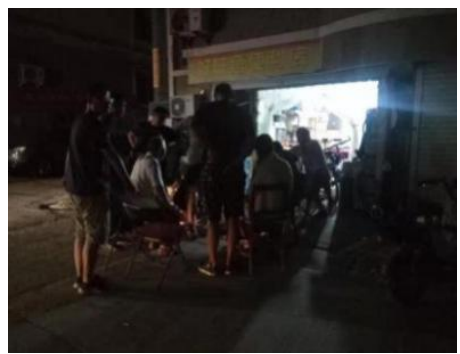

(Figure 12)

Cape of good hope

"cultural point" 6

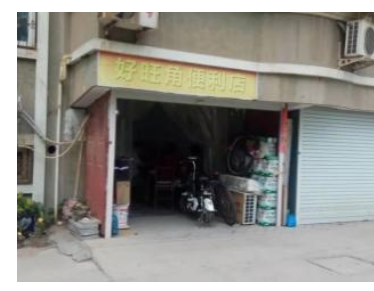

(Figure 9)

Cape of good hope

"cultural point" 3

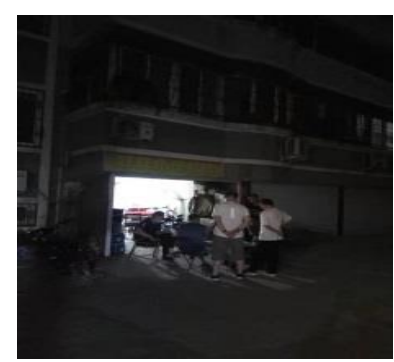

(Figure 13)

Cape of good hope "cultural point" 7

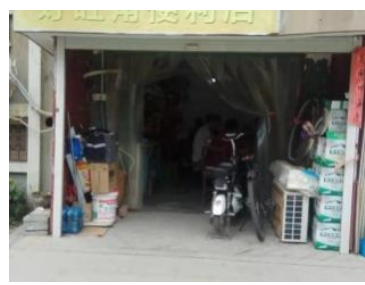

(Figure 10)

Cape of good hope "cultural point" 4

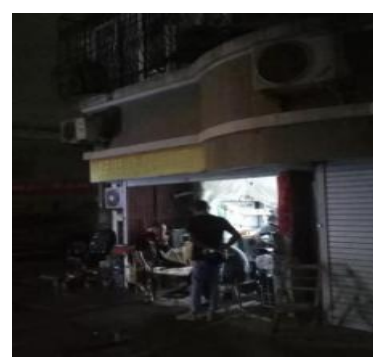

(Figure 14)

Cape of good hope "cultural point" 8

Table 2. The state table of "culture point"

\begin{tabular}{lllll}
\hline Title & Place & Time & Activity & State \\
\hline Figure 7 & Residential area gate & $09: 00$ & None & Daily business \\
\hline Figure 8 & Cape of good hope "cultural point" & $12: 00$ & None & Close down \\
\hline Figure 9 & Cape of good hope "cultural point" & $15: 00$ & Mahjong & $\begin{array}{l}\text { Weekend and } \\
\text { holidays }\end{array}$ \\
\hline Figure 10 & Cape of good hope "cultural point" & $15: 00$ & Mahjong & $\begin{array}{l}\text { Weekend and } \\
\text { holidays }\end{array}$ \\
\hline Figure 11 & $\begin{array}{l}\text { Residential area trunk road (cultural } \\
\text { point function overflow) }\end{array}$ & $\begin{array}{l}\text { Chinese } \\
\text { Cape of good hope "cultural point" }\end{array}$ & $\begin{array}{l}\text { Weekend and } \\
\text { holidays }\end{array}$ \\
\hline Figure 12 & $\begin{array}{l}\text { (outdoor) } \\
\text { Figure 13 }\end{array}$ & $\begin{array}{l}\text { Cape of good hope "cultural point" } \\
\text { (outdoor) }\end{array}$ & $\begin{array}{l}\text { Chinese } \\
\text { chess }\end{array}$ & $\begin{array}{l}\text { Weekend and } \\
\text { holidays }\end{array}$ \\
\hline Figure 14 & $\begin{array}{l}\text { Cape of good hope "cultural point" 22:00 } \\
\text { (outdoor) }\end{array}$ & $\begin{array}{l}\text { Chinese } \\
\text { chess }\end{array}$ & $\begin{array}{l}\text { Non-holiday } \\
\text { Chinese } \\
\text { chess }\end{array}$ & $\begin{array}{l}\text { Non-holiday } \\
\text { (Rainy) }\end{array}$ \\
\hline
\end{tabular}

Note: The cape of good hope "cultural point" is covered almost all-day through observation 


\section{Conclusion}

The difference between urban and rural places is reflected not only on a material level, but also on a spiritual level. The current residential area has been unable to return to the ancient notion of "neighborhood" due to the city's massive individualization and heterogeneity, but the public spirit, which is similar to the concept of residential area, is vitally needed by contemporary people. It's an intangible bond that may bring people of all skin colors, races, beliefs, ages, and origins together to form "people on one boat." Based on literature review, this paper carries out empirical data collection and case analysis to provide reference for the reconstruction of new living areas, especially old residential areas in the future. It is suggested to make active use of the existing conditions, increase cultural communication space and supporting living facilities, beautify the environment as well as organically renew it, so as to make it spend its old age in peace for the rest of its life of 50 years.

\section{Attachments}

\subsection{Attachment 1: Permanent responsibility monument of the project (Figure 15)}

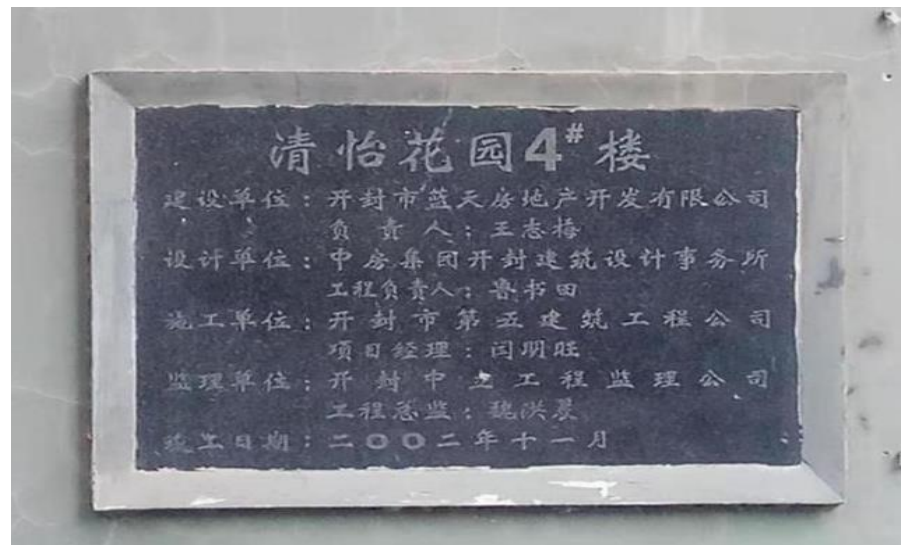

Figure 15. Permanent responsibility monument of the project

\subsection{Attachment 2: Interview method (covering all levels of the residential area) ${ }^{[6,7]}$}

\subsubsection{Interviewee A: Cape of good hopestore manager and culture point manager}

(1) Author: What time do you open these days? Point manager: It's usually from 7:00 to 10:00 in the evening. It's not necessarily during the day.

(2) Author: Your shop has been open for years, isn't it? Point manager: It was there when the residential area is completed.

(3) Author: How long has our Chinese chess stand been going on? Point manager: At least ten years.

(4) Author: Why did the stall break up before nine last night? Point manager: Because the people on the second floor have a problem, saying that too much movement affects the rest.

\subsubsection{Interviewee B: Elderly housewives of residential area residents}

(1) Author: How to evaluate the environment and public facilities? Housewives: Not perfect, there is not enough public green space, and there is no place for activities in the residential area, let alone public facilities

(2) Author: What would you like to do after dinner? Housewife: Either watch TV or go out and walk around the residential area. The municipal environment outside is pretty good

(3) Author: Do you have any expectations for the residential area? Housewife: Improve the environment and add more places where everyone can go 


\subsubsection{Interviewee $C$ : Elderly guard of the residential area}

(1) Author: Why does the cape of good hope leave work so early today?

(2) Guard: Usually after 10 o'clock, I don't know why it closed early at 9 o'clock today. Maybe the shopkeeper has something to do.

(3) Author: What time does it usually open?

(4) Guard: About 7 p.m.

(5) Author: Where is the real estate management in our resident area? I've lived so long that I don't know.

(6) Guard: Right behind you (an old wooden table full of parcels) the real estate management is combined with the guard.

\subsubsection{Interviewee D: Senior chess player}

(1) Author: What time do you usually open your stall? Do you basically come every day? Senior chess player: Usually at six or seven in the evening.

(2) Author: Do you usually have no other activities after work? Senior chess friends (looking left and right): There is no place to go in our community.

\subsubsection{Interviewee $\mathrm{E}$ : Residential area architect and designer (online chat)}

(1) Author: I have a question to ask you. Did the specification not require relevant supporting utilities when you designed it?

(2) Architect: The design of the design institute is based on the control regulations.

(3) Author: Is it positioned as affordable housing? In 2002, very few residential buildings will set up project responsibility monument, and generally the key large-scale projects can enjoy this treatment.

(4) Architect: I can't remember this clearly.

\subsubsection{Interviewee $F$ : Residential area police (telephone interview)}

(1) Author: If the residential area I live in is transformed, I'd like to hear your suggestions as a local regional policeman from the perspective of a manager?

(2) Local regional police: First of all, of course, we should start from ensuring the safety of residents in the residential area, and then we can talk about others. From the point of view, safety is the most basic

(3) Author: In the previous questionnaire survey, although residents have a negative opinion on the environment and supporting facilities of the community, they generally evaluate the public security of the residential area well.

(4) Local regional police: (Laughter) Our work starts from the safety of the residential area. Your residential area should be built into a smart residential area. This is the future development direction. For example, residential area access control face recognition, unit access control face recognition, and even entry. The wall at the intersection of the residential area is equipped with camera and other measures, and the unit organizes us to study in the developed provinces of the south.

\subsubsection{Interviewee G: Real estate developers (telephone interview)}

(1) Author: Qingyi Garden is just a residential area. Why did you set up a project responsibility monument in 2002? At that time, this was generally the only treatment for super large projects.

(2) Developers: The residential area is an affordable housing and a government project, so a monument must be erected according to the official requirements. At that time, it was to reduce the selling price as much as possible, because it was a limited price project (1200 yuan $/ \mathrm{m}^{2}$ ) 
(3) Author: Yeah, I remember when I moved here, I heard it was a little over 1,000, but now it's several times that.

(4) Everyone's response to housing quality and residential area security is still good, but what we are talking about now is the residential area environment and supporting facilities.

(5) Developers: At that time, affordable housing was basically like this. People would consider others only when they were satisfied with their living.

\subsubsection{Interviewee H: Planning Bureau}

(1) Author: The only public facility in Qingyi Garden where I live is a guard. Even the property is shared with the guard. What is the reason?

(2) Planning Bureau: There was no urban and rural planning law in 2002. At that time, it should be constructive detailed planning.

(3) Author: Now the country is carrying out the transformation of old residential areas. Do you have any specific suggestions for Qingyi Garden?

(4) Planning Bureau: Starting from water, electricity and heating infrastructure, the green space environment should be well done to meet the basic needs of the doormen, proper consideration should be given to parking, and additional construction is not recommended

\subsection{Attachment 3: Questionnaire method}

From the ten A4 valid responses, it is concluded that: Residents are generally dissatisfied with the existing environment, and the older they are, the more they care about public supporting facilities, and the higher their requirements are.

\subsection{Attachment 4: Factor induction ${ }^{[9]}$}

(1) If the environmental elements in general residential areas are extracted and stripped out, they can be roughly classified into 17 categories: 1 . Flat ground, 2. Seats, 3. Ceiling, 4. Children's entertainment facilities, 5. Bushes, 6. Trees, 7. Lawn, 8. People, 9. Sports venues, 10. Trails, 11. Waterscape, 12. Sports facilities, 13. Community avenue, 14. Spatial area, 15. Spatial location, 16. Pedestrian and vehicle go separately, 17. Residential structure. Under different activity modes, the demand levels for environmental elements are different.

(2) Rest and leisure interaction space model: The necessary elements are 1, 2, 3, 8, 15, 16, 17; The secondary elements are 4, 5, 6, 9, 10, 11, 14; Unnecessary elements are 7, 12, 13.

(3) Parent child space mode: The necessary elements are 1, 2, 3, 4, 5, 16; The secondary elements are 6, $7,8,9,10,12,14,15,17$; Unnecessary elements are 11, 13.

(4) Exercise space mode: The necessary elements are 1, 2, 3, 9, 14, 16, 17; The secondary elements are $5,6,8,9,10,12,15$; Unnecessary elements are 7, 11, 13.

\section{Disclosure statement}

The author declares no conflict of interest.

\section{References}

[1] Pang LB, Tian N. 2020, "Discussion on The White Pagoda Temple" 2020 Theme Activity: "Old City, New Street,” World Architecture, 11(024). 
[2] Sun Y, Zhu Y, 2020, A Preliminary Study on Scattered Space in Old Residential Areas from the Perspective of Daily Life ----- Taking Nanjing Wangfuyuan Community as an Example. Huazhong Architecture. 38(07), 62-68.

[3] Zhao XM, Guo WW, Shi JR, 2017, Aging Appropriate Configuration Mode of Outdoor Environmental Elements in Residential Areas Based on the Types of Daily Activities of the Elderly Architecture Journal; February 2017, 48-52.

[4] Jan Gail, 2002, Communication and Space. Communication and space. China Architecture Publishing. October 2002.

[5] Jacobs J, 2005, The Death and Life of American Big Cities. Yilin Press; May 2005.

[6] Maslow, 2007, The Theory of Human Motivation. China Renmin University Press.

[7] Li B, 2008, Environmental Behavior Theory of Environmental Behavior and Its Extension. Architecture Journal, (2): 30-33. 